\title{
Enamel Reduction Techniques in Orthodontics: A Literature Review
}

\author{
Dr Christos Livas, Dr Albert Cornelis Jongsma and Prof. Yijin Ren*
}

Department of Orthodontics, University Medical Centre Groningen, University of Groningen, Groningen, The Netherlands

\begin{abstract}
Artificial abrasion of interproximal surfaces has been described for almost seventy years as orthodontic intervention for achievement and maintenance of ideal treatment outcome. A variety of terms and approaches have been introduced throughout this period implying a growing clinicians' interest. Nevertheless, the widespread recognition of enamel stripping technique was initiated by the advent of bonded orthodontic attachments and a 2-article series of Sheridan in the 80 's. Since then, experimental and clinical research has been focused on the investigation of instrumentation efficacy and potential iatrogenic sequelae related to interproximal stripping. This review discusses the evolution, technical aspects and trends of enamel reduction procedures as documented in the literature.
\end{abstract}

Keywords: Interproximal Enamel Reduction, Air-Rotor Stripping, Nonextraction orrthodontic treatment, Tooth alignment, Treatment outcome stability, Anterior region esthetics.

\section{INTRODUCTION}

Reduction of the mesiodistal dimensions of the teeth is a common practice in orthodontic treatment with fixed and clear plastic appliances [1]. Regardless of the term used, such as 'interproximal enamel reduction' ('IER') [2], 'airrotor stripping' ('ARS') [3], 'slenderizing' [4] or 'reproximation' [5], the abrasion of interproximal enamel surfaces is intended to improve tooth alignment and long-term maintenance [6]. The aim of this article is to provide, on the basis of the existing literature, insight into the historical development of the stripping concept, an updated clinical step-bystep guide, and answers on plausible questions that may arise to potential and current users.

\section{THE HISTORICAL BACKGROUND}

Already in 1944, Ballard [7] advocated stripping of the proximal surfaces of the mandibular anterior segment to correct a lack of harmony in tooth size. A few years later, Hudson [8] described in detail a stripping technique utilizing metallic strips, followed by polishing and fluoride preventive measures. Peck and Peck [5] observed that well-aligned mandibular incisors have significantly lower mesiodistal/faciolingual indices than those of crowded incisors, and recommended stripping for addressing tooth shape deviation. Tuverson [9] pointed out that correction of discrepancies in anterior interocclusal dental arch length may be accomplished by mesiodistal crown reduction of the lower anterior teeth. In the same year, Boese [10] based on the increased stability of mandibular arches 4 to 9 years post-treatment, proposed reproximation in combination with circumferential supracrestal fiberotomy to enhance orthodontic treatment

*Address correspondence to this author at the Department of Orthodontics, University Medical Centre Groningen, University of Groningen, Hanzeplein 1, BB72,9713GZ Groningen, The Netherlands; Tel: +31 503610111 ; Fax: +31 50361 9712; E-mail: y.ren@dmo.umcg.nl results. Despite the promising results of the preliminary reports, the use of full-arch banding procedures suspended the growth of the stripping concept for decades. It was in the mid-80's that the ARS-technique of Sheridan attracted worldwide interest from clinicians. In two consecutive articles by Sheridan $[11,12]$, grinding of interdental enamel was presented as an alternative to extraction or expansion procedures in cases of mild to moderate crowding. Finally, Zachrisson [13] recommended enamel reshaping to improve anterior esthetics, i.e. to prevent or reduce interdental gingival retraction ('black triangles) that becomes evident after alignment of crowded anterior segments. Indicative of the ongoing development of enamel reduction techniques is the almost two times increase of clinical use of anterior stripping between 1986 and 2008 in a United States survey of orthodontic diagnosis and treatment procedures [14].

\section{INTERPROXIMAL ENAMEL REDUCTION (IER) IN SIX STEPS}

Several IER methods have been introduced and progressively modified over the years. The sequence of clinical steps can be summarized as follows:

1. Comprehensive planning: Study cast measurements can determine the required amount of correction [15]. Ideally, a diagnostic set-up will supplement treatment planning and visualize the final position and morphology of teeth. The use of calibrated radiographic images to determine the exact amount of enamel that can be removed, though recommended by various authors [16-18], might not be feasible for routine clinical application.

2. Access to the interproximal areas: As a general rule, placement of fixed appliances and correction of rotations are recommended prior stripping [19]. An initial phase of levelling and aligning will establish proper contact points. Visibility and mechanical access to the 


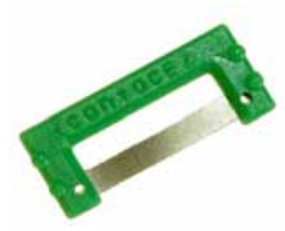

A

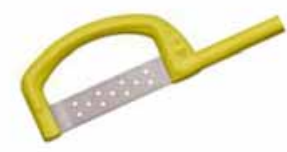

D

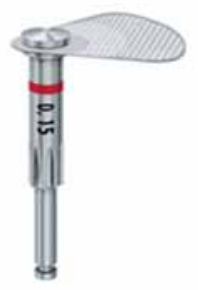

G

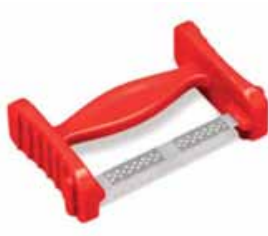

B

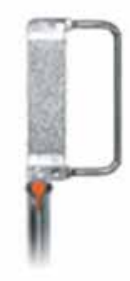

E

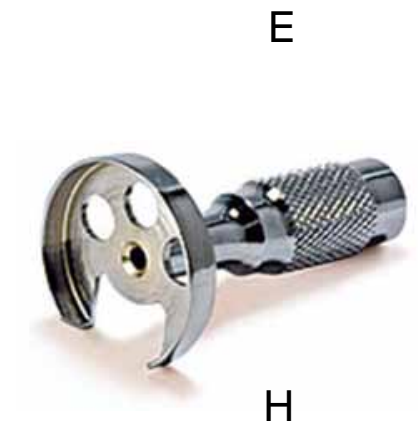

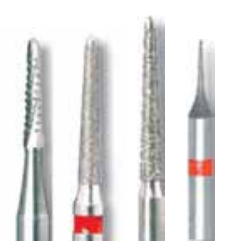

C

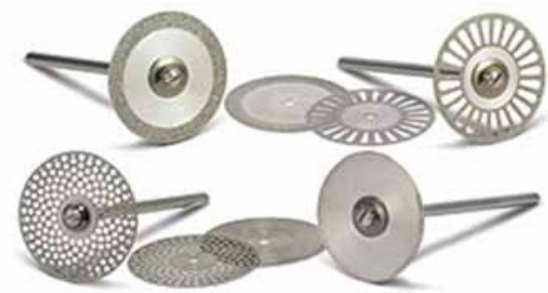

$\mathrm{F}$

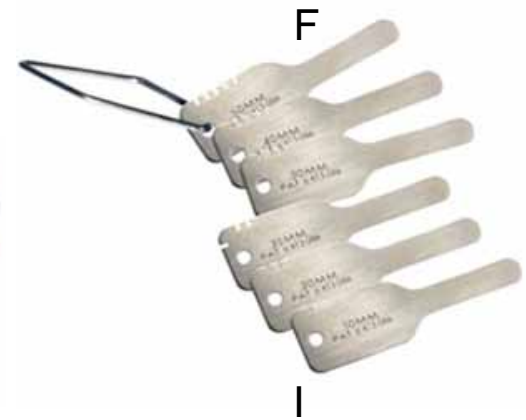

Fig. (1). Commercially available enamel reduction accessories. (A) ContacEZ Dental Strip, ContacEZ Company, Vancouver, WA, United States. (B) ET Flex ${ }^{\mathrm{TM}}$ Brasseler USA, Savannah, GA, United States. (C) Safe tipped ARS (STARS) burs, Raintree Essix, Inc. Metairie, LA, United States. (D) IDEAL® Interproximal Strip, Dentsply International, York, PA, United States. (E) Intensiv Ortho Strip System, Axis Dental, Coppell, TX, United States. (F) Galaxy ${ }^{\mathrm{TM}}$ Diamond Discs: Double sided-, double sided perforated-, double sided mesh, single sided diamond discs, Ortho Technology, Inc.; Tampa, FL, United States. (G) Oscillating segment disc, KOMET USA, Rock Hill, SC, United States. (H) Diamond Disc Safety Guard, Ortho Technology, Inc.; Tampa, FL, United States. i. Interproximal Gauge Set, KOMET USA, Rock Hill, SC, United States.

proximal surfaces will be further improved by means of a coil-spring, separator or wooden wedge.

3. Protection of the soft tissues: According to ARS guidelines [1], an .020-.030" brass or steel indicator wire should be placed gingival to the contact point to protect interdental tissue. The interference of a metal separator or a wedge will also minimize the risk for interproximal gingival lesions. Zachrisson [20] endorses a four-handed approach for tongue protection when a revolving diamond disc is used without a tongue and lip retractor in place. Zhong et al. [15] observed no soft tissue lesions during the stripping procedure apart from minor papillary incisions that were not described as painful by the patients. These authors concluded that the use of an oscillating perforated diamond-coated disc for enamel reduction eliminates the need for lip or cheek protectors.

4. Interproximal enamel removal: Mesiodistal enamel reduction is performed by either manual or mechanical methods (Fig. 1A-G). The early use of handheld abrasive strips has been criticized as time consuming process, hardly applicable in the posterior teeth, and producing irreversible residual furrows on the treated surfaces. Nowadays hand-operated strips (Fig. 1A, B) are reserved for minor enamel removal cases and as either introductory or finishing stripping procedure. In an update of the ARS technique, Chudasama and Sheridan [1] suggested the use of a safe-tipped ARS bur (Fig. 1C) to reduce interproximal enamel and prevent scarring of the proximal walls. Alternatively, metallic strip systems (Fig. 1D, E), diamond discs (Fig. 1F) or the most recently developed, segment discs adapted to a shuttle head with oscillation movement (Fig. 1G) have become increasingly popular. Segment disc systems enhance further visual and geometric access in relation to full $360^{\circ}$ discs [14]. Disc guards (Fig. 1H) that fit over the handpiece or contra-angle mounted diamond coated stripping discs can be used to protect the adjacent tooth that is not being slenderized. The orthodontist is generally advised to be conservative in initiating stripping procedures. Small enamel amounts should be ground symmetrically from all contact areas before maximum acceptable removal per site is reached. The progress of interproximal reduction can be quantified by means of commercially available thickness/leaf gauges (Fig. 1I).

5. Finishing and polishing of enamel surfaces: The interproximal corners are rounded with a cone-shaped triangular diamond bur [2]. With fine sand and cuttle 


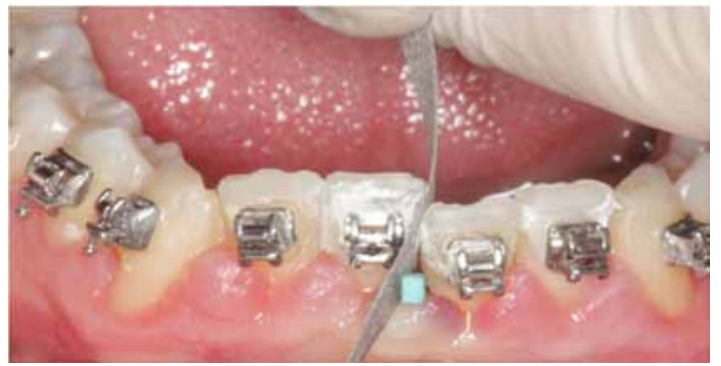

A

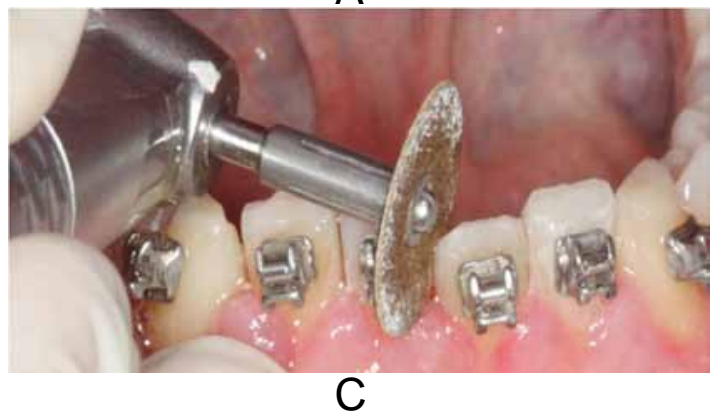

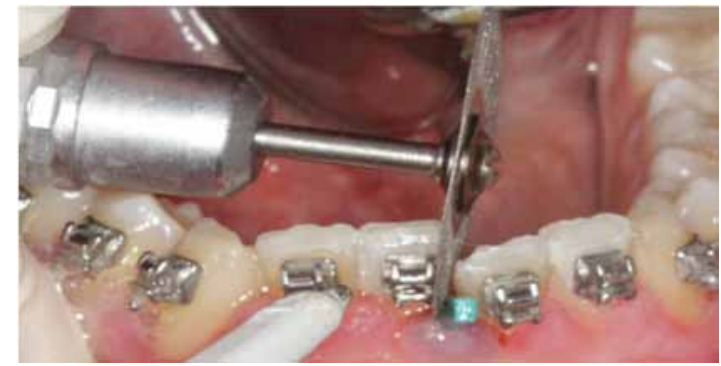

B

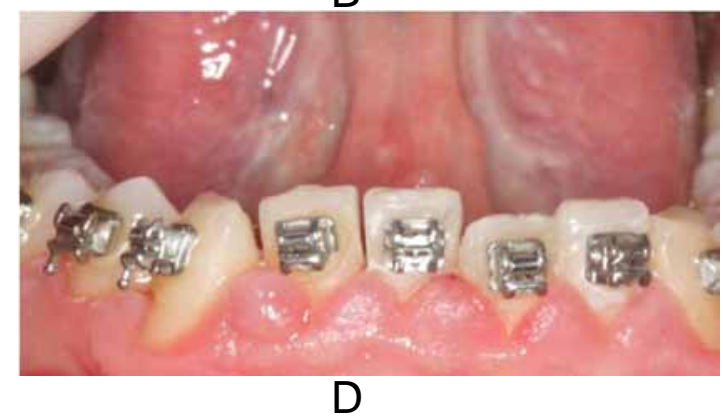

Fig. (2). Demonstration of interproximal enamel reduction method (frontal view). (A) Initial enamel amount removed by a handheld abrasive strip. Interdental tissues protected using a wooden wedge. (B) Main interproximal removal carried out by single sided diamond disks. Note the air syringe used for necessary cooling. (C) Polishing of treated surfaces by means of fine sand discs. (D) Final outcome.

discs (Sof-lex disks, 3M ESPE Dental Products, St. Paul, MN, United States) and finishing diamonds, proximal walls can be contoured to an acceptable morphology and texture. Final smoothing may be performed with even finer finishing instruments or $37 \%$ phosphoric acid gel ${ }^{1}$ as substantiated by Joseph and colleagues [21]. However, other authors [22, 23] have expressed their concerns regarding chemical stripping due to the susceptibility of the etched enamel to demineralization. Furthermore, though in vitro studies have confirmed a smoother surface of proximal sealants compared with intact [24], and stripped enamel [25], the use of sealants after stripping is clinically seldom possible. Lastly, technical difficulties in maintaining a dry working field, delay of the intraoral remineralization process, and cytoxicity effects have been used against sealing of the proximal enamel surfaces [15].

6. Topical fluoride treatment: To amplify the remineralization capacity of the abraded proximal surfaces, it is prudent to prescribe a fluoride gel after ARS $[1,26]$. On the other hand, Zachrisson ${ }^{20}$ considers unnecessary a special topical fluoride application on ground and polished tooth surfaces, and recommends it only in the presence of tooth thermal sensitivity when a twice-daily mouthrinsing with weak fluoride solution is used. An overview of treatment procedures and progress is illustrated in the case report of Fig. (2) and (3).

\section{HOW MUCH OF THE INTERPROXIMAL ENAMEL CAN BE SAFELY REMOVED?}

It is now widely accepted that $50 \%$ of proximal enamel is the maximum amount that can be stripped without causing dental and periodontal risks [19]. As first stated by Sheridan
[11], a potential gain of $2.5 \mathrm{~mm}$ and $6.4 \mathrm{~mm}$ of space may be anticipated by enamel removal from five anterior contacts and eight buccal contacts in an arch respectively. Stroud and et al. [27] estimated that enamel reduction of mandibular premolars and molars may provide $9.8 \mathrm{~mm}$ of additional space. Following the latest update [1], a measured $1 \mathrm{~mm}(.5$ mm per proximal surface) can be removed from the contact points of the buccal section, while stripping of the lower incisors should not exceed $.75 \mathrm{~mm}$ at each contact point due to the thinner proximal walls. Nonetheless, the orthodontist should not underestimate the variations in proximal enamel thickness among tooth categories and ethnic groups [17, 18], and customize the enamel surface preparation according to individual's characteristics. It is also useful to relate the amount of enamel that can be removed to the actual shapes of teeth, restorations and crownss [9]. The amount of gained space can be substantial in teeth with deviating morphology, and especially triangular-shaped teeth.

\section{HOW CAN THE EFFECTS OF STRIPPING-INDUCED HEAT BE PREVENTED?}

Frictional heat is a registered side effect of stripping procedures using rotary instruments. It is known from fundamental research that temperature increases more than $5.5^{\circ} \mathrm{C}$ in the dental pulp may lead to irreversible structural changes [28]. Other short-term [29] and long-term [30] studies on remodeling of teeth showed that extensive grinding of enamel, even to the extent that dentin is exposed, can be done safely, if two prerequisites are taken care of; water and air cooling are used and the prepared tooth surfaces are smooth and self-cleansing. Baysal and colleagues [31] recorded a significant temperature rise in high-speed stripping with a tungsten carbide, and stressed the need for simultaneous coolant application. Sheridan [26] suggests in particular the use of water spray with the ARS technique to reduce any 

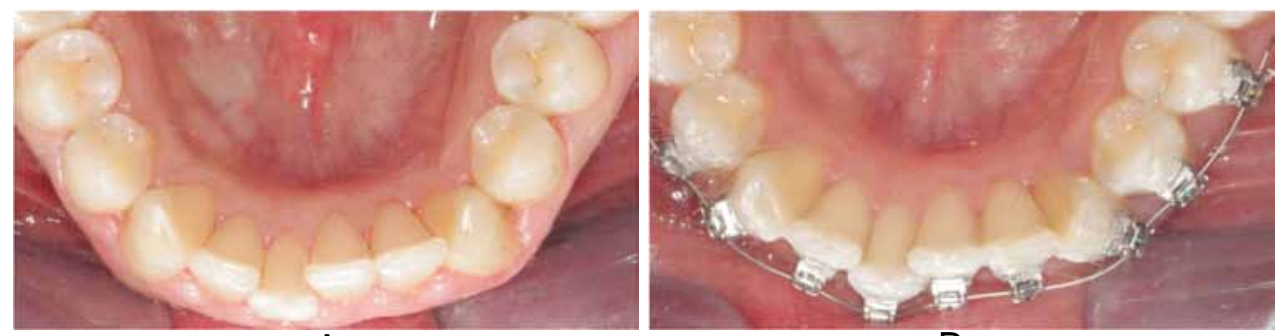

A
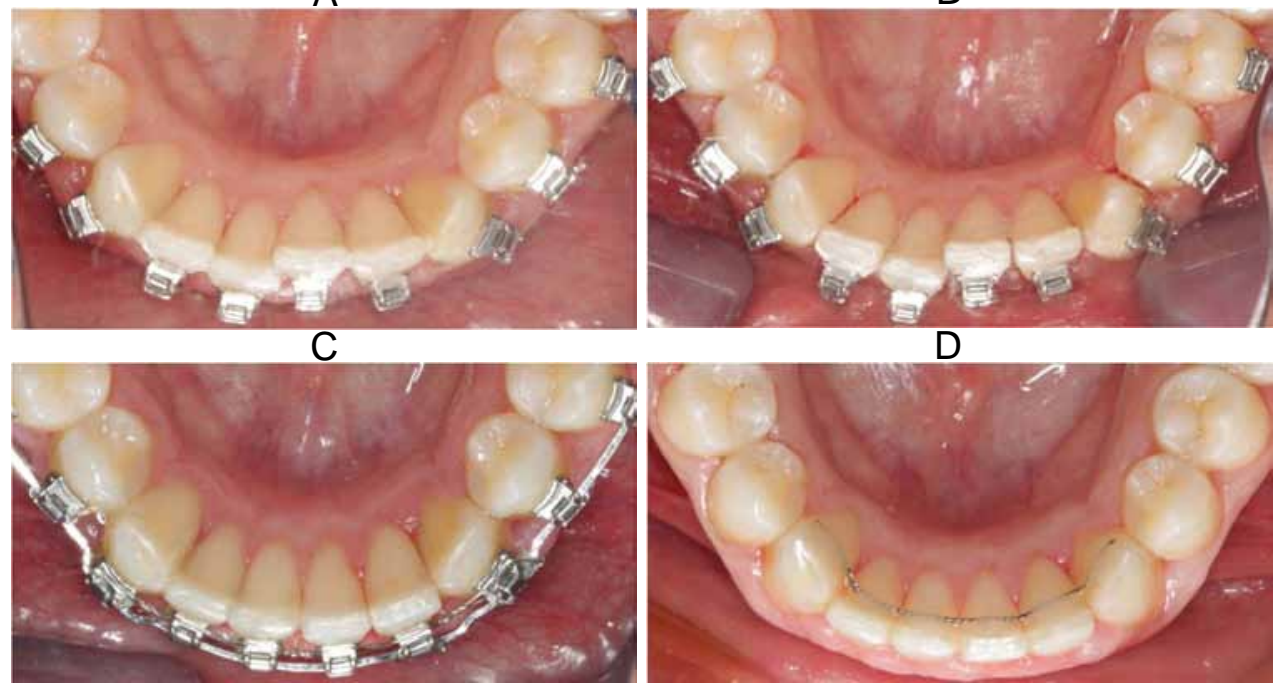

$\mathrm{E}$

$\mathrm{F}$

Fig. (3). Treatment progress (occlusal view). (A) Pretreatment crowded anterior mandibular segment. (B) Fixed appliances placed for a short period. (C) After aligning, access to interproximal areas is facilitated. (D) Interproximal enamel reduction is completed. (E) Further alignment improvement is achieved. (F) End of treatment, bonded lingual retainer in place.

pain and dissipate the generated heat. Zachrisson [32] recommends, for greater visibility and optimal results, air stream cooling by a dental assistant while performing interdental enamel reduction with extrafine diamond disks. Several authors $[19,26]$ recommended the use of new instruments for each stripping case to avoid discomforting thermal insults.

\section{ARE THERE MORPHOLOGIC DIFFERENCES BE- TWEEN STRIPPED AND INTACT ENAMEL?}

It has been proven by Scanning Electron Microscopic (SEM) observations [21-23, 25, 33] that all stripping methods dramatically affect the enamel morphology by producing rougher surfaces and furrows compared with untreated surfaces. Surface roughness can be significantly decreased by thorough polishing $[25,34]$. Stripping protocols that include enamel preparation with abrasive strips [23, 34], tungsten carbide burs $[22,35]$ or oscillating perforated diamondcoated discs [15], followed by finishing with Sof-Lex discs might result in polished enamel surfaces which are smoother than intact enamel. From a practical point of view, the rougher the surface resulting from enamel reduction, the more difficult it is to achieve a perfectly smooth surface by polishing. As a consequence, the finer the grain size used for removing enamel, the easier and less time-consuming is the subsequent finishing [36]. Moreover, larger-diameter SofLex disks, a new set of discs per interproximal surface and longer polishing times have been described to ensure an ideal polishing outcome [15].

\section{DOES STRIPPING INCREASE THE SUSCEPTIBIL- ITY OF TEETH TO CARIES AND PERIODONTAL DISEASE?}

The findings that the iatrogenic enamel furrows of stripping procedures may facilitate plaque accumulation, and persist one year after appliance removal [33] raised questions about the potential long-term increase of caries susceptibility of the abraded tooth surface. Accidentally introduced proximal steps during grinding have been also claimed to cause future cavities [29]. Experimental results [16] showed that air-rotor stripping increased significantly the incidence of demineralization on human proximal enamel. Follow-up studies $[2,32,37,38]$ with more than 5 years elapsed posttreatment time yielded contradictory evidence; overall low rates of new interproximal caries were observed ranging from 0 to 4.6 per cent $[2,37]$. The difference between teeth subjected to enamel reduction and control teeth was not statistically significant. It is likely that in clinical conditions remineralization from regular fluoride intake, and the natural interproximal enamel abrasion will restore the affected surfaces in the long term [32]. Observational studies [10, 37] that investigated the periodontal health implications of interdental stripping up to 9 years after treatment demonstrated no significant differences in gingival index and alveolar crest height. Zachrisson and colleagues [2] used detailed clinical and radiographic methods to evaluate soft and hard tissue complications in 61 subjects that received mesio-distal enamel reduction more than 10 years previously. The authors 
observed no signs of gingival recession or thinning of the labial gingivae in $93 \%$ of the patients, an insignificant 0.2 $\mathrm{mm}$ difference in crestal bone height between study and control group, and no reduction of mesio-distal bone widths between the roots in the mandibular anterior region.

\section{SHOULD THE CLINICIAN APPLY MEASURES TO PREVENT POSTSTRIPPING INTERPROXIMAL EN- AMEL CARIES?}

Plaque control methods, topical use of concentrated fluoride mouthrinses and dentifrices, and part-time wear of a thermoformed retainer containing fluoridating solution have been recommended to avoid possible detrimental effects of enamel reduction [21, 23]. Exposure of chemically stripped enamel surfaces to low concentrations of calcium-fluoride solution for 5- and 10-hour periods have been found to produce marked crystal growth in vitro [21]. Nevertheless, it is questionable whether fluoride treatment results in clinically significant benefits. Brudevold and colleagues [39] confirmed a relatively rapid-within one hour- remineralization effect of saliva on abraded bovine enamel. Remineralization was also evident nine months after air-rotor stripping on non-fluoridated premolar proximal surfaces [40]. Caries experiments as well showed that short term use of high and low dosage fluoride supplements, topical gel and dentifrice respectively, reduced the demineralization compared to no fluoride receiving group [16]. In this context, researchers [38] evaluated caries risk of ARS-prepared surfaces in orthodontic patients 6 years post-treatment, and concluded that the application of topical fluoride products in individuals regularly exposed to fluoridated water and fluoridecontaining toothpaste may not provide any additional benefit. In the last few years, based on the claimed effectiveness of casein phosphopeptide-amorphous calcium phosphate (GPP-ACP) in the regression of post orthodontic white spot lesions [41], GPP-ACP topical application has been introduced for interdental stripping [42].

\section{CONCLUSION}

The available literature indicates that reduction of interproximal enamel surfaces represents a valid therapeutic modality in the hands of the orthodontist. This technique, when carried out properly, and in specific circumstances, may assist achievement of treatment objectives without compromising integrity of the dental and periodontal tissues.

\section{CONFLICT OF INTEREST:}

The authors confirm that this article content has no conflicts of interest.

\section{ACKNOWLEDGEMENTS:}

Declared none.

\section{REFERENCES}

[1] Sheridan JJ. Guidelines for contemporary air-rotor stripping. J Clin Orthod 2007; 41: 315-20.

[2] Zachrisson BU, Nyøygaard L, Mobarak K. Dental health assessed more than 10 years after interproximal enamel reduction of mandibular anterior teeth. Am J Orthod Dentofacial Orthop 2007; 131: 162-9.

[3] Sheridan JJ. Air-rotor stripping. J Clin Orthod 1985; 19: 43-59.
[4] Broadbent JM. Recontouring teeth for excellence in orthodontic case finishing. Part I: Section Two \& Three. Air-rotor Slenderizing (ARS). Funct Orthod 1992; 9: 4-6, 8-16, 8-24.

[5] Peck H, Peck S. An index for assessing tooth shape deviations as applied to the mandibular incisors. Am J Orthod 1972; 61: 384401.

[6] Rossouw PE, Tortorella A. Enamel reduction procedures in orthodontic treatment. J Can Dent Assoc 2003; 69: 378-83.

[7] Ballard ML. Asymmetry in tooth size: A factor in the etiology, diagnosis, and treatment of malocclusion. Angle Orthod 1944; 14 : 67-71.

[8] Hudson AL. A study of the effects of mesio-distal reduction of mandibular anterior teeth. Am J Orthod 1956; 42: 615-24.

[9] Tuverson DL. Anterior interocclusal relations. Part I. Am J Orthod 1980; 78: 361-70.

[10] Boese LR. Fiberotomy and reproximation without lower retention, nine years in retrospect: part II. Angle Orthod 1980; 50: 88-97.

[11] Sheridan JJ. Air-rotor stripping. J Clin Orthod 1985; 19 :43-59.

[12] Sheridan JJ. Air-rotor stripping update. J Clin Orthod 1987; 21: 781-88.

[13] Zachrisson BU. Interdental papilla reconstruction in adult orthodontics. World J Orthod 2004; 5: 67-73.

[14] Keim RG, Gottlieb EL, Nelson AH, Vogels DS 3rd. 2008 JCO study of orthodontic diagnosis and treatment procedures, part 1: results and trends. J Clin Orthod 2008; 42: 625-40.

[15] Zhong M, Jost-Brinkmann PG, Zellmann M, Zellmann S, Radlanski RJ. Clinical evaluation of a new technique for interdental enamel reduction. J Orofac Orthop 2000; 61: 432-9.

[16] Twesme DA, Firestone AR, Heaven TJ, Feagin FF, Jacobson A. Air-rotor stripping and enamel demineralization in vitro. Am J Orthod Dentofacial Orthop 1994; 105: 142-52.

[17] Hall NE, Lindauer SJ, Tüfekçi E, Shroff B. Predictors of variation in mandibular incisor enamel thickness. J Am Dent Assoc 2007; 138: 809-15.

[18] Macha Ade C, Vellini-Ferreira F, Scavone-Junior H, Ferreira RI. Mesiodistal width and proximal enamel thickness of maxillary first bicuspids. Braz Oral Res 2010; 24: 58-63.

[19] Pinheiro MLR. Interproximal Enamel Reduction. World J Orthod 2002; 3: 223-32.

[20] Zachrisson BU. Actual damage to teeth and periodontal tissues with mesiodistal enamel reduction ("stripping"). World J Orthod 2004; 5: 178-83.

[21] Joseph VP, Rossouw PE, Basson NJ. Orthodontic microabrasive reproximation. Am J Orthod Dentofacial Orthop 1992; 102: 351-9.

[22] Piaccentini C, Sfondrini G. A scanning electron microscopy comparison of enamel polishing methods after air-rotor stripping. Am J Orthod Dentofacial Orthop 1996; 109: 57-63.

[23] Arman A, Cehreli B, Ozel E, Arhun N, Cetinsahin, Soyman M. Qualitative and quantitative evaluation of enamel after various stripping methods. Am J Orthod Dentofacial Orthop 2006; 130: 131.e7-e14.

[24] Sheridan JJ, Ledoux PM. Air-rotor stripping and proximal sealants: an SEM evaluation. J Clin Orthod 1989; 23: 790-4.

[25] Grippaudo C, Cancellieri D, Grecolini ME, Deli R. Comparison between different interdental stripping methods and evaluation of abrasive strips: SEM analysis. Prog Orthod 2010; 11: 127-37.

[26] Sheridan JJ. John J. Sheridan, DDS, MSD, on air-rotor stripping. J Clin Orthod 2008; 42: 381-8.

[27] Stroud JL, English J, Buschang PH. Enamel thickness of the posterior dentition: its implications for nonextraction treatment. Angle Orthod 1998; 68: 141-6.

[28] Zach L, Cohen G. Pulp response to externally applied heat. Oral Surg Oral Med Oral Pathol 1965; 19: 515-30.

[29] Zachrisson BU, Mjör IA. Remodeling of teeth by grinding. Am J Orthod 1975; 68: 545-53.

[30] Thodarson A, Zachrisson BU, Mjör IA. Remodeling of canines to the shape of lateral incisors by grinding: a long-term clinical and radiographic evaluation. Am J Orthod Dentofacial Orthop 1991; 100: 123-32.

[31] Baysal A, Uysal T, Usumez S. Temperature rise in the pulp chamber during different stripping procedures. Angle Orthod 2007; 77: 478-82.

[32] Zachrisson BU, Minster L, Ogaard B, Birkhed D. Dental health assessed after interproximal enamel reduction: caries risk in posterior teeth. Am J Orthod Dentofacial Orthop 2011; 139: 90-8 
[33] Radlanski RJ, Jäger A, Schwestka R, Bertzbach F. Plaque accumulation caused by interdental stripping. Am J Orthod Dentofacial Orthop 1988; 94: 416-20.

[34] Danesh G, Hellak A, Lippold C, Ziebura T, Schafer E. Enamel surfaces following interproximal enamel reduction with different methods. Angle Orthod 2007; 77: 1004-10.

[35] Lucchese A, Porcu F, Dolci F. Effects of various stripping techniques on surface enamel. J Clin Orthod 2001; 35: 691-5.

[36] Hein C, Jost-Brinkmann P-G, Schillai G. Oberflächenbeschaffenheit des Schmelzes nach approximalen Beschleifen - Rasterelektronenmikroskopische Beurteilung unterschiedlicher Polierverfahren. Fortschr Kieferorthop 1990; 51: 327-35.

[37] Crain G, Sheridan JJ. Susceptibility to caries and periodontal disease after posterior air-rotor stripping. J Clin Orthod 1990; 24: 8495.
[38] Jarjoura K, Cagnon Genevieve, Nieberg L. Caries risk after interproximal enamel reduction. Am J Orthod Dentofacial Orthop 2006; 130: 26-30.

[39] Brudevold F, Tehrani A, Bakhos I . Intraoral mineralization of abraded dental enamel. J Dent Res 1982; 61: 456-9.

[40] El-Mangoury NH, Moussa MM, Mostafa YA, Girgis AS. In-vivo remineralization after air-rotor stripping. J Clin Orthod 1991; 25: 75-8.

[41] Chen H, Liu X, Dai J, Jiang Z, Guo T, Ding Y. Effect of remineralizing agents on white spot lesions after orthodontic treatment: a systematic review. Am J Orthod Dentofacial Orthop. 2013; 143: 376-82.

[42] Giulio AB, Matteo Z, Serena IP, Silvia M, Luigi C. In vitro evaluation of casein phosphopeptide-amorphous calcium phosphate (CPPACP) effect on stripped enamel surfaces. a SEM investigation. J Dent 2009; 37: 228-32.

(C) Livas et al.; Licensee Bentham Open.

This is an open access article licensed under the terms of the Creative Commons Attribution Non-Commercial License (http://creativecommons.org/licenses/by-nc/3.0/) which permits unrestricted, non-commercial use, distribution and reproduction in any medium, provided the work is properly cited. 